\title{
Comparing personality change of the newly employed and old employees working at the offshore oil industry: a cross-sectional study
}

\begin{abstract}
Introduction: Recent research has shown that job conditions can affect employees' personality traits. The present study is an attempt to investigate the effect of working in offshore oil industry on employees' personality.

Method: The present study was conducted by comparing the personality traits of two groups of offshore oil workers with different duration of employment. The sample consisted of 88 staff ( 44 newly employed and 44 employed for 4 to 8 years) that were selected and homogenized. Newly employed consist of all employed persons at 2017 and old employees were matched with newly ones based on age, education, and marital status. The NEO personality questionnaire (long form) was used to collect data on personality traits. Data were analyzed by measuring the effect size.
\end{abstract}

Results: The results showed that longer occupation at offshore jobs is associated with personality changes. So that the scores of workers with a higher length of employment compared to those with less than one year of work experience were higher in neuroticism and lower in extroversion, agreeableness, and consciousness.

Conclusion: These findings suggest that the offshore oil industry businesses create changes in the personality traits of employees, which can affect their compatibility with everyday life and in particular their relationships in the family. The results are discussed and the limitations of this study are explained.

Keywords: personality change, offshore employees, oil industry, big five
Volume 9 Issue 6 - 2018

\author{
Abbas Roozbehani, Morteza Tarkhan, Ahmad \\ Alipour, Majid Saffarina \\ Department Psychology, Payam Noor University, Iran
}

Correspondence: Abbas Roozbehani, Department Psychology, Payam Noor University, Iran, Email arozbehani@yahoo.com

Received: October 23, 2018 | Published: November 16, 2018

\section{Introduction}

Personality is a relatively constant pattern of thinking, feeling, and behaving that distinguishes one from others. The definition of personality relies more on stability rather than changes during the life. Some studies suggest that people adopt different levels of personal traits based on time and situation changes. ${ }^{1}$ What are the sources of these changes? Today, there is little doubt that personality changes reflect the genetics and the environmental impacts. ${ }^{2}$ In terms of genetics, personality traits are essentially the temperaments that "develop through childhood and reach a mature form in adulthood; thereafter they are stable in cognitively intact individuals" ${ }^{\prime 3}$ and shall not change by an external factor such as culture ${ }^{4}$ or the events and life experiences. Based on five large twin studies in 5 different countries, Plomin R et al., 5 concluded that genes only explain half of the changes in traits of neuroticism and extraversion. Other perspectives such as Social Investment Theory ${ }^{6}$ or social genetic theory ${ }^{7}$ state that life events like marriage, parenting, entering a job, and generally investment in social situations and playing different roles lead to personality development in adulthood. Over the years, there has been strong evidence that the social roles (e.g., having a job) are the source of personality changes.

Researchers have found a strong relationship between the job requirements as a social role and personality traits. ${ }^{7,8} \mathrm{~A}$ role that requires a high level of consciousness is more likely to improve this trait in a person; while someone who enters a job with low responsibility may also show a low score in consciousness. Studies in this field have shown that increasing career role engagement causes normative personality development. Wille et al., ${ }^{9}$ showed that change in career role engagement was associated with change in four of the big five personality traits over the same time interval. Only for openness no significant association was found between the trait change and change in career role engagement. For example, normative decreases in neuroticism were related to increases in director, presenter, and inspiratory roles. Similarly, normative increases in conscientiousness were more related to increases in director, inspirator, guide, and expert roles. Extroversion was more related to presenter, director, inspirator, and guide roles, and agreeableness was related to Guide role. There are growing findings that work experience may play a role in the development of adult personality traits. ${ }^{10,11}$ The reason is that the work environment leads to such a change by providing a boost or punishment for some behaviors. ${ }^{10}$ These changes can also occur due to several sources of stress such as time pressure and heavy workload. ${ }^{8}$

Other studies have shown that there is a reciprocal relationship between job characteristics and personality changes. For example, Le et al., ${ }^{12}$ found evidence that working conditions are related to the relative changes in personality traits. For example, relative increase of a genetic positive emotionality is consistent with a person's ability to work, sense of freedom and lack of workrelated stress. The people who reported that their job allows them 
to use their skills make decisions and provide a safe work environment find themselves more ambitious and assertive from late adolescence to early adulthood. Similarly, the individuals who reported that their job does not allow them to use their skills, is stressful, does not provide a safe environment and has a higher level of risk, showed negative emotionality from adolescence to early adulthood. ${ }^{12}$

A number of studies in the field of organizational psychology demonstrate that business experiences may change personality during the work life. First, Cohn and Schooler found that employees who work in complex businesses become mentally more flexible. Robert et al., ${ }^{11}$ showed that several aspects of employee work experiences such as career progression, job satisfaction, and engagement with work predict changes in personality. Wille et al., ${ }^{9}$ showed that the Big Five personality traits shape and influence job characteristics. It is possible that these personality changes are due to the fact that the conditions of the work environment clearly encourage or punish a particular type of behavior. ${ }^{10}$ In short, it can be said that the effects of job on changes in personality traits have recently attracted the attention of researchers. Research shows that personality can be influenced by social roles (such as being employed). However, few prospective studies have addressed the question of how occupationalrelated events can lead to personality change and studies in this area are limited..$^{13}$ The robust opinion obtained is that entering a job is related to the increase in conscientiousness. ${ }^{13}$ However, the research also has had some methodological problems. For example, studies have been conducted on limited businesses and so far no studies have been done on jobs with specific characteristics, such as work in the offshore oil industry. Only one study indicates that offshore employees are on average more likely than the general population to show higher extraversion and lower neuroticism. In other words, they may represent a combination of a stable extrovert personality that can show the compatible personality. ${ }^{14}$ A qualitative study showed that by increasing the length of employment in offshore oil jobs, characteristics such as irritability, isolation, impatience, impulsive behavior and aggression would increase ${ }^{15}$ The present study aims to fill the research gap in this area, as well as to study the effects of working in oil fields that have special conditions (such as the existence of many stressors, and distance from family for several weeks) on the personality traits of the staff. The present study is designed to answer the following questions: Does work in offshore oil fields have any effect on employee's personality traits? Is the length of stay in this job related to changes in personality traits?

\section{Method}

\section{Type of research}

This cross-sectional study was carried out on a group of offshore employees working in the oil industry.

\section{Subjects}

Participants included 88 employees who working in offshore oilfields (Iranian Offshore Oil Company). The first group consisted of 44 participants who had recently been employed (less than one year) from 2017 for work at. The second group consisted of 44 veteran workers who work between 5 to 10years in the same offshore oilfield in Kharg Island. Due to the low volume of recruiting personnel, the sample size of the second grope equally to the sample size of the first group was randomly selected among the employees of Offshore Oilfield in Kharg Island. Attempts were made to select the subjects of the second group based on similarities in educational and marital status with the first group (Table 1).

\section{Measures}

The Persian version of NEO questionnaire (Long form) was used to collect data on personality traits of employees. This questionnaire assesses the Big Five traits of personality (Neuroticism, Extraversion, Openness to experience, Agreeableness and Conscientiousness). Each trait has subscales ( 6 subscales for each category). Scoring questions are as follow: strongly disagree (0) disagree (1), neutral (2), agree (3) and strongly agree (4). The questionnaire was validated on a sample of 502 people in Shiraz. ${ }^{16}$ Cronbach's alpha coefficients for N, E, O, $\mathrm{A}, \mathrm{C}$ were $0.81,0.71,0.57,0.71$ and 0.83 , respectively. Retest validity within 6months were $0.53,0.74,0.76,0.60$ and 0.75 for N, E, O, A and $\mathrm{C}$, respectively.

\section{Results}

A summary of the demographic information is given in Table 1 . Average education for the two groups is near to each other. On age, there are small differences between groups (especially singles from groups of newly employed are younger than other groups).

Table I Demographic data of the sample $(\mathrm{N}=88)$

\begin{tabular}{lllll}
\hline Work experience & Marital status & N & Average years of education & Average age(years) \\
\hline \multirow{2}{*}{ under one year } & Single & 22 & 17.55 & 27.77 \\
& Married & 22 & 17.64 & 30.77 \\
& Single & 22 & 16.64 & 30.32 \\
4 to 8years & Married & 22 & 17.24 & 32.14 \\
\hline
\end{tabular}

Table 2 provides the means and standard deviations of the five scales for new and old employees. For data analysis, the effect size was used. The standard deviation of both control and experimental groups were similar but in scale A, SD for newly employed was slightly bigger than those employed for 4 to 8 years. This shows that the variance of responses to this scale has been greater in the former group compared to the latter. Also, this is true in subscale E.
We used Cohen's d, the most frequently used effect size measure for measuring standardized differences between means. Cohen proposed standards of "small" $(\mathrm{d}=.2)$, "medium" $(\mathrm{d}=.5)$, and "large" $(d=.8)$ to provide a rough interpretation of the magnitude of effects. As it is obvious from Table 2, for all means, except in scale $\mathrm{O}$, the magnitude of effect size is above medium. 
Table 2 Comparison of two groups with different work experiences on personality traits

\begin{tabular}{|c|c|c|c|c|c|c|c|c|}
\hline \multirow{2}{*}{ Variable } & \multicolumn{3}{|c|}{ Newly employed } & \multicolumn{5}{|c|}{ Employed for 4-8years } \\
\hline & $\mathbf{N}$ & $\mathbf{M}$ & SD & $\mathbf{N}$ & $\mathbf{M}$ & SD & $\mathbf{t}$ & dc \\
\hline C & 34 & 147.06 & 16.22 & 34 & 134.56 & 17 & $3.07 * *$ & 0.75 \\
\hline A & 34 & 127.33 & 13.92 & 34 & $|19.4|$ & 11.04 & $2.57^{*}$ & 0.63 \\
\hline O & 34 & 109.15 & 13.78 & 34 & 105.18 & 12.8 & 1.22 & 0.29 \\
\hline $\mathrm{E}$ & 34 & 121.73 & 17.96 & 34 & 111.85 & 14.1 & $2.50 *$ & 0.61 \\
\hline$N$ & 34 & 54.79 & 21.83 & 34 & 72.15 & 22.65 & $-3.19 * *$ & 0.78 \\
\hline
\end{tabular}

$* * p<0.01, *^{*}<0.05$

\section{Discussion and conclusion}

The present study aimed to investigate the effect of duration of employment on the personality changes among offshore oil staffs. Studies show that there is a relationship between personality traits changes and work. ${ }^{10,11,17}$ These changes are probably due to stressrelated work (control and demand) ${ }^{8}$ or reward and punishment that the job provides to developing certain types of behavior and attitudes. ${ }^{10}$ The results of present study show that the duration of employment is effective on all personality traits except openness to experience. As work experience increases, adaptive traits are decreased (conscientiousness, agreeableness, and extraversion) and maladaptive traits increase (neuroticism).

Conscientious people show characteristics such as robustness, accuracy, willingness to work and trustworthiness. The findings of the present study show that people enter the work with higher consciousness, and the level of this trait gradually decreases with increased duration of employment, which also predicts a gradual decrease in productivity in offshore oil jobs. This finding is inconsistent with findings that emphasize the positive impact of work on the task force. ${ }^{13}$ Recently, in a survey of 1814 employees over 5years, $\mathrm{Wu}^{8}$ showed that job stress caused by demand/control can reduce the extraversion and consciousness and increase neuroticism. In other words, one of the reasons for the reduction of this trait can be caused by the stressors in oil industry. Routine stressors in offshore oil jobs include physical pressures, noise, temperature, ship and helicopter transport, living and working conditions, interpersonal relationships, and living far from communities (social isolation). ${ }^{14,18}$ Another reason for this decline in consciousness may be related to the organizational culture. It is likely that the atmosphere governing the organizational culture (at least in the organization where the study was conducted) is more indirectly encouraging disorder, lack of commitment, irresponsibility, and not being on time.

On the other hand, people with more experience in offshore jobs achieve higher scores in neuroticism. Higher scores on this scale indicate anxiety, depression, anger, hatred, discomfort, and a variety of negative emotions. Also, people who score higher on this scale may be at risk of a variety of psychiatric problems. It seems that work environment stressors and worker lifestyle can be effective in increasing neuroticism in offshore jobs. ${ }^{14,18}$ Increasing neuroticism can also be attributed to job dissatisfaction, ${ }^{19}$ low income compared to job hardiness, ${ }^{12,20}$ and increased stressors. ${ }^{21}$

Agreeableness represents the attributes such as trust, allegiance, modesty, understanding others, empathy and simplicity, which expresses a positive or negative orientation towards others. A person who has a high score on this scale is essentially human-friendly, shows sympathy for others, and is interested in helping people. Instead, a person who has a low score on this scale is usually selfish, suspicious of others' intentions, and competitive with the colleagues. The proportion of people aged 4 to 8years is lower than that of new employees at this scale, which indicates that work conditions and other factors tend to reduce the adaptability of employees with other people. Findings of $\mathrm{Wu}^{8}$ showed that job stress (including job demand and job control) has no effect on the agreeableness, but increased job control is associated with an increase in the agreement. The conditions of work at sea seem to have reduced staff agreeableness. It is likely that the atmosphere governing interpersonal relationships in satellite work is progressing over time to the extent that initial trust-based friendships are replaced with distrust because of behaviors such as neglect, jealousy, and unhealthy competition. This, along with the organization's sense of discrimination towards individuals can lead to reduced compliance and increase of interpersonal conflicts.

In extroversion, as duration of occupancy in offshore increased, the employees lost their decisiveness more and become more passive and lazy. Demand and control stress reduces extroversion. ${ }^{8}$ In this study, job stress in marine oilfields can be a factor in reducing employee extroversion. It can also be caused by lifestyle as well as the effects of being away from the community. Workers in offshore oil jobs spend only 14days working in their jobs, distinguishing them from those working in cities. In this way, onshore workers, apart from their job duties, must also perform their home tasks (such as shopping and assisting in the house chores). However, during the absence of a husband due to his offshore oil job, a woman carries the house burden alone, and the man has no other duty in the workplace except his job duties. It seems that this will reduce the activity and increase laziness among the offshore oil workers. Separation from the community and reduced social interactions will probably result in marginalization of workers in social relationships. They may deliberately or compulsorily assign their social responsibilities to others (spouse, father or mother), and may, therefore, get more isolated.

In addition to stress and working conditions, It is also suggested that personality changes in offshore oil jobs can be due to other sources. For example, neuroticism may be more sensitive to stressors, and consciousness, besides stress, also may be affected by organizational culture. The agreeableness can be influenced by interactions with colleagues and extroversion also may be affected by lifestyle and social isolation. However, it requires more research; as $^{2}$ believe that various events of life incite different degrees of emotions, cognition, and behavioral responses, and can have different effects on the degree of change or the stability of the personality traits. The findings of the 
present study also show that the notion that offshore oil job affects the behavioral aspects of personality (such as conscientiousness, extroversion, and agreeableness) more than the cognitive (openness to experience) and emotional (neuroticism) aspects ${ }^{13}$ can be somewhat false. In fact, this research has shown that some occupations can affect all aspects of the employee in such a way that the undesirable aspects of personality (such as neuroticism) increase and desirable aspects (such as extroversion, agreeableness, and consciousness) decrease. These changes, which include becoming more nervous, less tolerant, reducing social interactions, and further isolation and reduction in conscientiousness, can have adverse effects on worker's adaptation to the everyday life. The numerous complaints of offshore oil workers about marital and child upbringing conflicts can be part of this personality changes. ${ }^{22}$ Therefore, it is recommended to provide a time limitation for occupation at offshore jobs to reduce the adverse effects on employee's personality and encourage them to leave the offshore oil jobs and join their families.

This study also had some limitations. Due to the time limit in this study, the cross-sectional method of study was used instead of the longitudinal method. One of the most important constraints is that because the exposure and outcome are simultaneously assessed, it is not possible to establish a true cause and effect relationship without longitudinal data. Although attempts have been made to reduce the individual differences between samples in this type of study, it is not possible to manipulate these differences so it can affect the outcome of the study. Therefore, in future studies, a longitudinal method is recommended. ${ }^{23-25}$

\section{Acknowledgments}

Here it is necessary to thank the officials of Iranian Offshore oil company (IOOC) for providing the facilities for the study. Without this help, the present study was not possible.

\section{Conflict of interest}

Author declares that there is no conflict of interest.

\section{References}

1. Fleeson W. Towards a structure- and process-integrated view of personality: Traits as density distributions of states. J Pers Soc Psychol. 2001;80(6):1011-1027.

2. Bleidorn W, Kandler C, Caspi A. The behavioral genetics of personality development in adulthood - Classic, contemporary, and future trends. European Journal of Personality. 2014;28:244-255.

3. McCrae RR, Costa PT. A five-factor theory of personality. In: LA Pervin, OP John, editors. Handbook of personality. New York: Guilford; 1999. p. 139-153.

4. McCrae RR, Costa PT, Ostendorf F, et al. Nature over nurture: Temperament, personality, and life span development. J Pers Soc Psychol. 2000;78(1):173-186.

5. Plomin R, Caspi A. Behavioral genetics and personality. In: Pervin LA, John OP, editors. Handbook of personality: Theory and research. New York: Guilford Press; 1999. p. 251-276.

6. Roberts BW, Wood D, Smith JL. Evaluating Five factor theory and social investment perspective on personality trait development. Journal of research in Personality. 2005;39(1):166-184.
7. Heller D, Perunovic WQE, Reichman, D. The future of person-situation integration in the interface between traits and goals: A bottom-up framework. Journal of Personality. 2009;43(2):171-178.

8. Wu, Chia-Huei. Personality change via work: a job demand-contro model of Big-five personality changes. Journal of Vocational Behavior. 2016;92:157-166.

9. Wille B, Beyers W, De Fruyt F. A transactional approach to person-environment fit: Reciprocal relations between personality development and career role growth across young to middle adulthood. Journal of Vocational Behavior. 2012;81(3):307-321.

10. Hudson NW, Roberts BW, Lodi-Smith J. Personality trait development and social investment in work. J Res Pers. 2012;46(3):334-344.

11. Roberts BW, Caspi A, Moffitt T. Work experiences and personality development in young adulthood. J Pers Soc Psychol. 2003;84(3):582-593.

12. Le K, Donnellan MB, Conger R. Personality Development at Work: Workplace Conditions, Personality Changes, and the Corresponsive Principle. J Pers. 2014;82(1):44-56.

13. Bleidorn W, Hopwood CJ, Lucas RE. Life events and personality trait change. J Pers. 2018;86(1):83-96.

14. Parkes KR. Psychosocial aspects of stress, health and safety on North Sea installations. Scand J Work Environ Health. 1998;24(5):321-333.

15. Roozbehani AS, Tarkhan M, Aghayusefi A. Personality changeability: A comparative study of the effects of length of employment on personality changes in offshore oil workers. Clinical psychology and personality-Daneshvar. In press.

16. Hagh-shenas Hassan. Standardization of the Neo Test, Revised Form Quarterly Journal of Thoughts and Behavior. 1998;16:38-47.

17. Wille B, De Fruyt F, Feys M. Vocational interests and Big Five traits as predictors of job instability. $J$ Vocat Behav. 2010;76(3):547-558.

18. Sutherland VJ, Cooper CL. Occupational stress in the offshore oil and gas industry. Int Rev Ergonomics. 1989;2:183-215.

19. Shiner RL, Masten AS, Roberts JM. Childhood personality foreshadows adult personality and life outcomes two decades later. J Pers. 2003;71(6):1145-1170.

20. Sutin AR, Costa PT, Miech R, et al. Personality and career success: Concurrent and longitudinal relations. Eur J Pers. 2009;23(2):71-84.

21. Leger KA, Charles ST, Turiano NA, et al. Personality and Stressor-Related Affect. J Pers Soc Psychol. 2016;111(6):917-928.

22. Parkes K, Carnell CS, Farmer LE. Living two lives, Perception, attitudes and experiences of spouses of UK offshore workers. Community, Work and Family. 2005;8(4):413-437.

23. Chen WC, Wong WT, Yu TS. Mental health issues in Chinese offshore oil workers. Occup Med (Lond). 2009;59(8):545-549.

24. Clark D, McCann K, Morrice K, et al. Work and marriage in the offshore oil industry. International Journal of Social Economics. $1985 ; 12(2): 36-47$

25. Kohn ML, Schooler C. Job conditions and personality: a longitudinal assessment of their reciprocal effects. AJS. 1982;87(6):1257-1286. 